\title{
The Potential of Trichoderma spp. Endophytes as Biological Control Agents Against Ceratocystis sp. Causes of Acacia Stem Rot Disease in vitro
}

\author{
Fifi Puspita ${ }^{1}$ Rachmad Saputra ${ }^{1, *}$ Nur Hasanah ${ }^{1}$
}

\author{
${ }^{1}$ Agrotechnology Department, Agriculture Faculty, Universitas Riau, Pekanbaru, 28293, Riau, Indonesia \\ *Corresponding author.rachmadsaputra@lecturer.unri.ac.id
}

\begin{abstract}
Ceratocystis sp. is an important pathogen in acacia plants. This pathogenic fungus causes stem rot disease which can cause the death of mature plants within 4 - 7 years with a disease attack percentage of nearly $80 \%$. The common controlling technique is carried out by using chemical pesticides, for that we need another alternative to reduce its negative impact, namely the use of Trichoderma spp. endophyte. This research aimed to determine the potential of the Trichoderma spp. endophytes in suppressing the development of the Ceratocystis sp. The study was conducted experimentally using a completely randomized design (CRD) consisting of 7 treatments with three replications, namely without Trichoderma sp. endophytic (E0), two isolates of T. virens endophytic of oil palm plants (E1-E2), one isolate of T. harzianum endophytic of rubber plants (E4), three isolates of Trichoderma sp. endophytic of acacia plants (E5-E7), and one isolate Trichoderma sp. endophytic of eucalyptus plant (E14). The parameters observed were the antagonistic ability, colony diameter, growth rate of Trichoderma spp. colonies, and its inhibition mechanism against Ceratocystis sp. Based on the results of this study, Trichoderma sp. endophytic E074 isolated from 4 years old Acacia crasicarpa had the highest antagonistic ability $(30.76 \%)$, diameter $(90 \mathrm{~mm})$, and growth rate $\left(33.33 \mathrm{~mm}^{-}\right.$day $^{-}$ ${ }^{1}$ ) compared to other isolates with hyperparasitic entrapment type.
\end{abstract}

Keywords: acacia, biological control, endophytes, Ceratocystis, Trichoderma

\section{INTRODUCTION}

Acacia plantations (Acacia crasicarpa) are industrial plantation forest commodities that have high economic value because they are widely used, especially as a source of raw material for the paper (pulp). One of the important diseases found in acacia is stem rot disease caused by Ceratocystis sp. Ceratocystis sp. is a pathogen that attacks forestry plants or industrial plants such as acacia plants with an attack percentage of nearly $80 \%$. Ceratocystis sp. can cause death in mature plants within a period of 4-7 years which is marked by yellowing of the leaves, drying up and the tree finally dying, the bark of the trunk becomes blackish-brown and cracked [1].

According to Accordi, Ceratocystis sp. is a pathogen that does not have an incubation period, so that when there is a fungal wound it will immediately colonize and infect, therefore fast and precise control is needed [2]. Control efforts have been made to overcome attacks by Ceratocystis sp. namely by controlling the technical culture, the use of resistant varieties and using synthetic chemical fungicides, but the use of synthetic chemical fungicides excessively can cause poisoning in humans, environmental pollution, death of non-target organisms and resistance to pathogens. Pathogen control techniques that are safer and more environmentally friendly are biological control by utilizing biological agents. Biological agents can be utilized, one of which is endophytic fungi. Endophytic fungi are fungi originating from plant tissue and do not harm their host plants [3].

One of the endophytic fungi that are often found and capable of acting as biological control agents is Trichoderma sp. This fungus can suppress disease development in plants, especially soil-borne pathogens through processes of mycoparasitism, competition, and antibiosis, which indirectly stimulate plant growth and induce resistance to disease [4].

The endophytic Trichoderma harzianum AK51 isolate from rubber plants has $70.6 \%$ inhibition power to control white root fungal disease in rubber plants [5]. Trichoderma virens endophytic fungus originating from oil palm roots is better, compared to the Trichoderma virens endophytic fungus originating from stems and midribs shown by the best antagonistic ability of $71.11 \%$ and the best antifungal compound of $25.74 \%$. and the inhibitory mechanism that occurs is antibiosis in inhibiting the growth of the fungus Rigidoporus microporus [6]. Trichoderma sp. local isolates can inhibit Ganoderma sp. in Acacia mangium plants with inhibition power ranging from $38.09 \%-58.06 \%$ [7]. Control of Ceratocystis sp. by 
using Trichoderma sp. endophytes have not been widely reported. The purpose of this study was to determine the effect of several Trichoderma sp. isolates endophytic and obtained the best isolates Trichoderma sp. endophyte to control Ceratocystis sp. in vitro.

\section{MATERIALS AND METHODS}

The research was conducted at the Laboratory of the Plant Protection Department of PT. Arara Abadi, Pinang Sebatang Village, Tualang District, Siak Regency, Riau. The research was conducted for 4 months from March to June 2019.

The materials used in this study were Trichoderma sp. endophytic origin of acacia and eucalyptus plants collected by the Laboratory of PT Arara Abadi R\&D Perawang, isolate Trichoderma sp. endophytic origin of oil palm, the collection of Fifi Puspita and isolates from Trichoderma sp. endophytic origin of rubber plants from the collection of Wilda Andini, a pathogenic isolate of Ceratocystis sp. (013C-R1) PT Arara Abadi R\&D Perawang laboratory collection, potato sucrose agar (PSA), streptomycin, 70\% alcohol, 96\% alcohol, distilled water, cotton, tissue paper, plastic wrap, aluminum foil and label paper.

The tools used in this study were stationery, ruler, camera, $9 \mathrm{~cm}$ diameter petri dish, bunsen lamp, cork borer (agar cutter), knife, binocular microscope, object glass, cover glass, measuring cup, Laminar Air Flow Cabinet (LAFC), oven, micropipette, spatula, scalpel, tweezers, loop needles, test tubes, Erlenmeyer, test tube, incubators and analytical scales.

This research was conducted experimentally using a completely randomized design (CRD) consisting of 7 treatments and 3 replications to obtain 21 experimental units. The treatments in this study were 7 isolates of Trichoderma sp. endophytic with high antagonistic ability (T) with high inhibition (> 50\%) as follows: T1 (Trichoderma virens isolate endophytic oil palm plant roots; T2 (Trichoderma virens endophytic isolate from stems of oil palm plants; T4 (Trichoderma harzianum isolate endophytic rubber plant roots); T5 (Trichoderma sp. endophytic E074 Acacia crasicarpa isolate 4 years; T6 (Trichoderma sp. endophyte E075 Acacia crasicarpa isolate 4 years); T7 (Trichoderma sp. endophytic E080 Acacia crasicarpa isolate 3 years) and T14 (Trichoderma sp. E022 endophytic Eucalyptus plant).

The observation parameter of this study was the antagonistic ability of several Trichoderma sp. Isolates. endophytes against Ceratocystis sp., colony diameter $(\mathrm{mm})$ and growth rate $\left(\mathrm{mm}\right.$. day $\left.^{-1}\right)$ isolates of Trichoderma sp. endophytic and hyperparasitic interaction type isolates Trichoderma sp. endophyte with high antagonistic ability against Ceratocystis sp.

The data obtained from the observations were analyzed descriptively and by variance. Descriptive data analysis includes the results of observations of the types of hyperparasitism. Data on the fungus Trichoderma sp. endophyte with high antagonistic ability against
Ceratocystis sp. and data is presented in tables and figures Analysis of variety includes inhibitory data of the fungus Trichoderma sp. endophyte, diameter and growth rate of the Trichoderma sp. endophyte which has high antagonistic ability against Ceratocystis sp. To compare the average between Trichoderma sp. Isolates. The endophyte was followed by further tests with Duncan's new multiple range test (DNMRT) at the 5\% level.

\section{RESULTS AND DISCUSSION}

\subsection{Antagonist Ability of Trichoderma sp. Endophyte Against Ceratocystis sp. In Vitro}

Antagonistic ability of 19 isolates of Trichoderma sp. endophytes against Ceratocystis sp. significant effect after analysis of variance. The results of the DNMRT follow-up test at the 5\% level can be seen in Table 1 .

Table 1 Antagonistic ability of Trichoderma sp. endophytes against Ceratocystis sp. 5 days after incubation in PSA medium.

\begin{tabular}{|c|c|}
\hline Isolat & Daya antagonis (\%) \\
\hline $\mathrm{T}_{1}$ & $21,61 \mathrm{bc}$ \\
\hline $\mathrm{T}_{2}$ & $20,83 \mathrm{bc}$ \\
\hline $\mathrm{T}_{4}$ & $21,33 \mathrm{bc}$ \\
\hline $\mathrm{T}_{5}$ & $30,76 \mathrm{a}$ \\
\hline $\mathrm{T}_{6}$ & $24,00 \mathrm{ab}$ \\
\hline $\mathrm{T}_{7}$ & $21,88 \mathrm{bc}$ \\
\hline $\mathrm{T}_{14}$ & $22,66 \mathrm{bc}$ \\
\hline
\end{tabular}

The numbers followed by the same lowercase letter are not significantly different after being transformed by $\sqrt{ }(y+0.5)$ according to the DNMRT test results at the 5\% level.

Table 1 shows that the T5 isolate has a high antagonistic ability to inhibit the growth of the fungus Ceratocystis sp. namely $30.76 \%$ and significantly different from other isolates and without Trichoderma sp. isolates. endophytic but not significantly different from isolate E6 because isolate $\mathrm{T} 5$ has a faster growth and can be seen in the measurement parameters of diameter and growth speed (Table 2) so that it can inhibit the pathogen Ceratocystis sp. because of competition for space and nutrition.

According to Harman et al. fast growing fungi can outperform in control of space and nutrition and the end can suppress the growth of their opponent's fungi, the competition is in obtaining nitrogen and carbon [8]. This is following the results of research by Hutabalian et al. stated that biological agents that have fast growth will have the ability to inhibit the growth of pathogens with higher competition for space and nutrients [9]. 
According to Sunarwati and Yoza, antagonistic fungi that have an inhibitory ability of $26-50 \%$ are included in the group of fungi that have the low antagonistic ability because the inhibitory ability of antagonistic fungi is influenced by several factors, one of which is the growth of the fungus itself [10]. Amaria states that fungal isolates that have high inhibitory ability are antagonistic fungi isolates whose colony growth is faster than pathogenic colonies [11]. This is in following what was stated by Octriana that antagonistic fungi can be categorized as having high inhibitory activity against pathogen growth if the percentage of inhibition reaches more than $60 \%$, but if the percentage of inhibition only reaches $30 \%$ then the antagonistic fungi can be categorized as having an inhibitory effect [12].
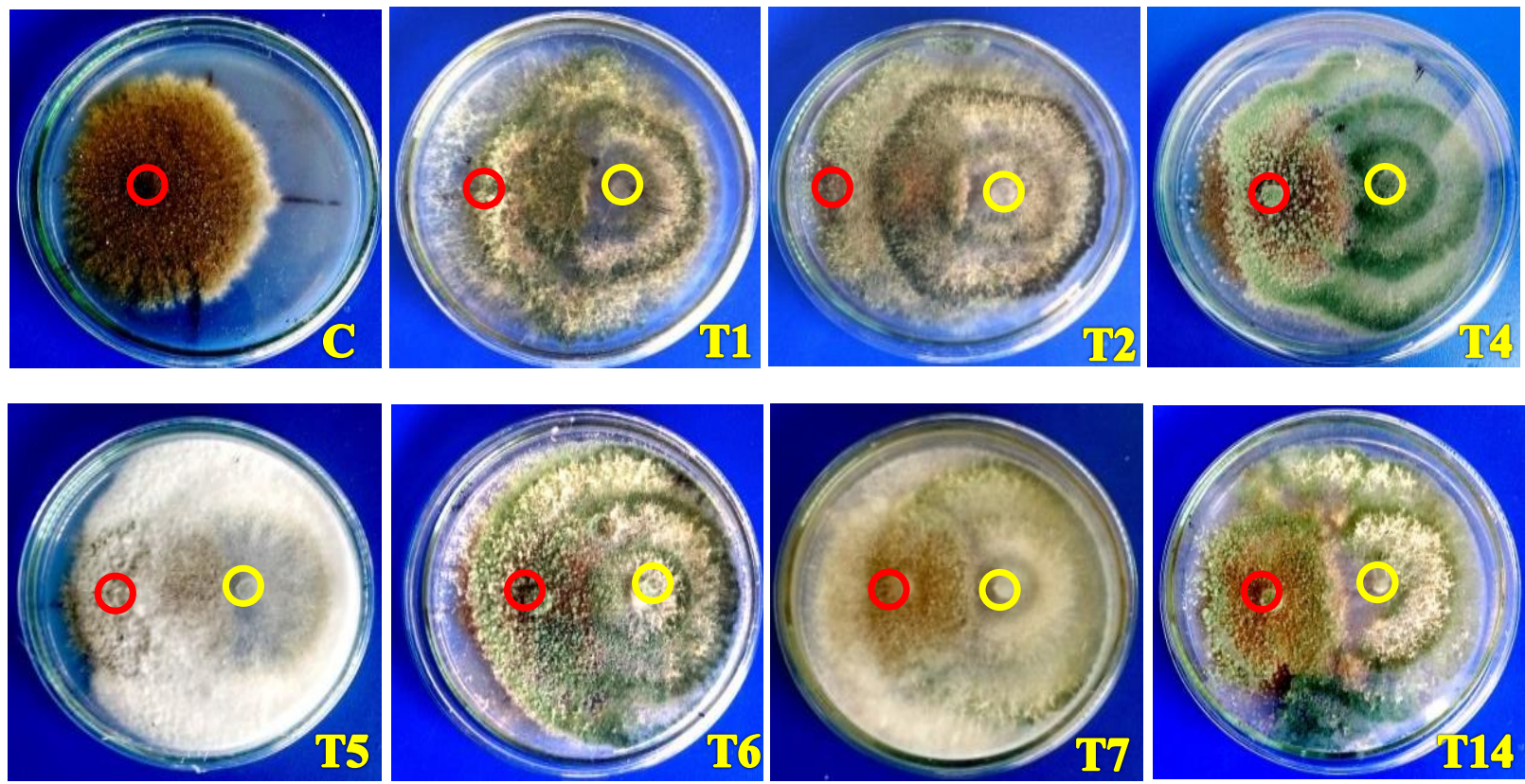

Figure 1 Antagonistic ability of Trichoderma sp. (yellow circle) against Ceratocystis sp. (red circle) on PSA medium. (C = control; T1, T2, T4, T5, T6, T7 and T14 = Trichoderma sp. isolates $)$

Based on Figure 4, it can be seen that 7 isolates (T1, T2, T4, T5, T6, T7 and T14) with moderate antagonistic ability did not form an inhibition zone but isolates of Trichoderma sp. endophytes have a mechanism of competition for space and nutrients in inhibiting the growth of the pathogenic fungus Ceratocystis sp. on PSA medium. Competition between Trichoderma sp. endophytes and Ceratocystis sp. occurs because of competition for nutrients from the PSA medium so that the fungus Trichoderma sp. Endophytes are superior in control of space and nutrition and can grow to meet PSA medium. This causes the growth of Ceratocystis sp. become obstructed. According to Melysa et al. antagonistic properties arise due to the competition that occurs between two types of fungi that are grown side by side [13]. This competition occurs due to the same needs of each mushroom, namely the need for a place to grow and nutrients from the media used to grow. Purwantisari and Hastuti reported that the faster the growth of antagonistic fungi, the more suppressed the growth of pathogenic fungi would be due to running out of growth space [14].

\subsection{The diameter and growth rate of Trichoderma sp. high antagonistic ability $\left(\right.$ mm.day $\left.^{-1}\right)$.}

The results of observing the diameter and growth rate of Trichoderma sp. endophytes with moderate antagonistic ability had a significant effect after analysis for variance. The results of the DNMRT follow-up test at the 5\% level can be seen in Table 2 .

Table 2 shows that the T5 isolate has a diameter and growth rate that tends to be high, namely $90.00 \mathrm{~mm}$ and

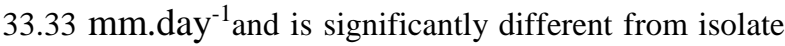
$\mathrm{T} 7\left(84.00 \mathrm{~mm}\right.$ and $\left.31.00 \mathrm{~mm} . \mathrm{day}^{-1}\right)$ but is different not real with other isolates. The growth of isolate T5 was very fast so that it was able to fill the growing space on the third day of observation. This is related to the results of the antagonistic ability of the fungus Trichoderma sp. endophytes that can compete in the struggle for space and nutrition with Ceratocystis sp. Hutabalian et al. also reported that the faster the growth of a biological agent, the higher its ability to suppress pathogen growth due to competition for nutrients and living space [9]. 
Based on Figure 2, it can be seen that the growth of isolates T5 was faster than isolates T4, T14, T1, T2, T6, and T7. This is following the opinion of Djafarudin that the growth rate of fungal colonies is an important factor in determining its potential as a biological agent against pathogens [15]. According to Gusnawathy et al. the ability of high growth rates is one of the main factors that determines the ability of an antagonistic organism to control diseases that attack plants, so that with this ability microorganisms can compete in control of space and nutrients [16].
Table 2 Diameter $(\mathrm{mm})$ and growth rate $\left(\mathrm{mm} \cdot \mathrm{day}^{-1}\right)$ of 7 isolates of Trichoderma sp. moderately inhibiting endophyte

\begin{tabular}{|c|c|c|}
\hline $\begin{array}{c}\text { Trichoderma } \\
\text { sp. isolates }\end{array}$ & Diameter $(\mathbf{m m})$ & $\begin{array}{c}\text { Growth rate } \\
\text { (mm.day }^{-1} \text { ) }\end{array}$ \\
\hline $\mathrm{T}_{1}$ & $85,66 \mathrm{abc}$ & $32,50 \mathrm{ab}$ \\
\hline $\mathrm{T}_{2}$ & $85,00 \mathrm{bc}$ & $31,83 \mathrm{ab}$ \\
\hline $\mathrm{T}_{4}$ & $89,33 \mathrm{ab}$ & $32,83 \mathrm{ab}$ \\
\hline $\mathrm{T}_{5}$ & $90,00 \mathrm{a}$ & $33,33 \mathrm{a}$ \\
\hline $\mathrm{T}_{6}$ & $84,66 \mathrm{bc}$ & $31,83 \mathrm{ab}$ \\
\hline $\mathrm{T}_{7}$ & $84,00 \mathrm{c}$ & $31,00 \mathrm{~b}$ \\
\hline $\mathrm{T}_{14}$ & $88,66 \mathrm{abc}$ & $32,83 \mathrm{ab}$ \\
\hline
\end{tabular}

The numbers followed by the same lowercase letter are not significantly different according to the results of the Duncan New Multiple Range Test (DNMRT) at the 5\% level.
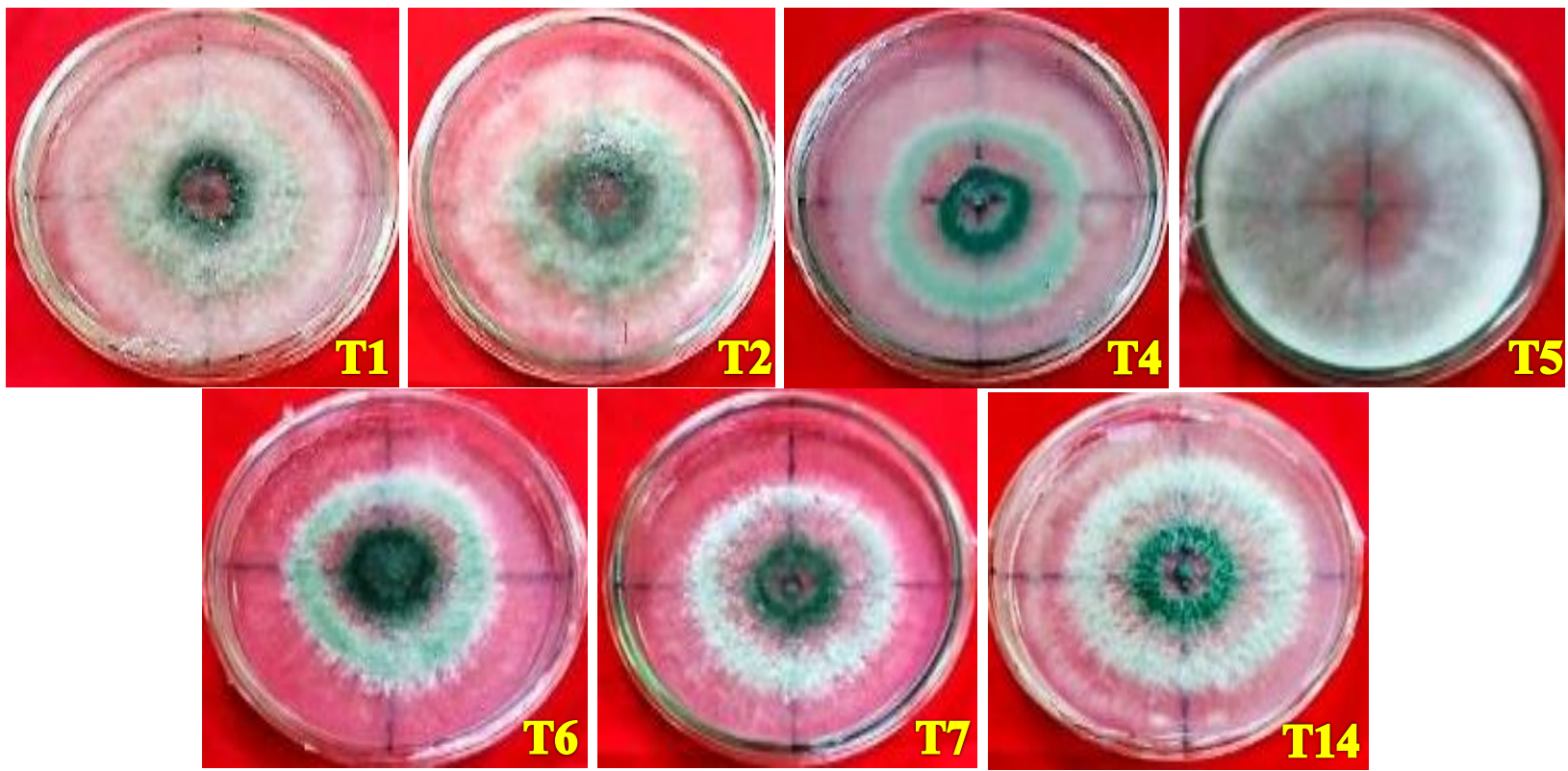

Figure 2 The diameter of the Trichoderma sp. endophytes 3 days after incubation in PSA medium. a) Isolate T1, b) Isolate T2, c) Isolate T4, d) Isolate T5, e) Isolate T6, f) Isolate T7, g) Isolate T14

\subsection{Trichoderma sp. Hyperparasitic Type. Endophyte with High Antagonistic Ability Against Ceratocystis sp.}

Trichoderma sp. Hyperparasitic type. endophyte with moderate antagonistic ability against the fungus Ceratocystis sp. has a hyperparasitic type based on the results of the hyperparasitic test. Hyperparasitic types can be seen in Table 3 and Figure 3.

Table 3 and Figure 3 shows that there are three types of hyphae interactions in Trichoderma sp. isolates. T1, T2, T4 and T6 isolates have interaction in the form of hyphal coiling and make the sticking and widing type that cause damage to the hyphae of Ceratocystis sp. This is suspected because the antagonistic fungi produce various chemical compounds that are toxic to Ceratocystis sp. Sunarwati and Yoza stated that the genus Trichoderma was able to inhibit the growth of pathogenic hyphae by producing gliotoxin and viridin antibiotics [10].

The interaction between $\mathrm{T} 4$ isolates and Ceratocystis sp. Attachment is an initial process in inhibiting pathogenic fungi from the hyperparasitic activity which results in the cessation of pathogenic growth. The results of Alamsyah's research state that the process of attaching hyphae have shown an initial interaction between antagonistic fungi, which then the hyphae will pierce and suck the contents of pathogenic hyphae cells, resulting in the cessation of the growth of pathogenic fungal hyphae [17]. 
The isolates of $\mathrm{T} 5$ and $\mathrm{T} 7$ show the entrapment type that causes the hyphae of Ceratocystis sp. does not develop and stop to growth. This is supported by the opinion of Kurnia et al. stated that the antagonistic hyphae that trap pathogenic hyphae will cause the pathogenic hyphae to not develop so that their growth stops [3].

The T14 isolate causes the growth of pathogenic hyphae break off and it can be seen that in some parts of the hyphae becomes clear. It is suspected that there is a lysis mechanism so that the growth of pathogenic fungal hyphae becomes abnormal. This is supported by the opinion of Sunarwati and Yoza which states that another way biological agents can inhibit pathogens is by lysis. Lysis, namely the mycelium of biological agents, is capable of destroying or cutting the mycelium from pathogens, which in turn causes the pathogen's death [10].
The lysis mechanism is characterized by changing the color of the pathogenic fungal hyphae to become clear and empty, then some break off and eventually destroy [18].

Table 3 Trichoderma sp. Types of hyperparasitic against Ceratocystis sp.

\begin{tabular}{|c|c|}
\hline $\begin{array}{c}\text { Trichoderma } \mathbf{s p .} \\
\text { isolates }\end{array}$ & Types of hyperparasitic \\
\hline $\mathrm{T}_{1}, \mathrm{~T}_{2}, \mathrm{~T}_{4}$ and $\mathrm{T}_{6}$ & Winding and Sticking \\
\hline $\mathrm{T}_{5}$ and $\mathrm{T}_{7}$ & Entrapment \\
\hline $\mathrm{T}_{14}$ & Lysis \\
\hline
\end{tabular}

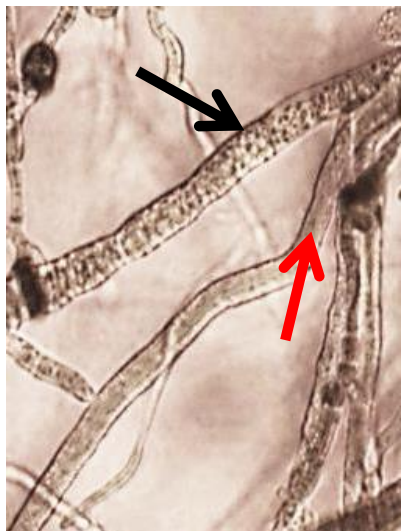

T1

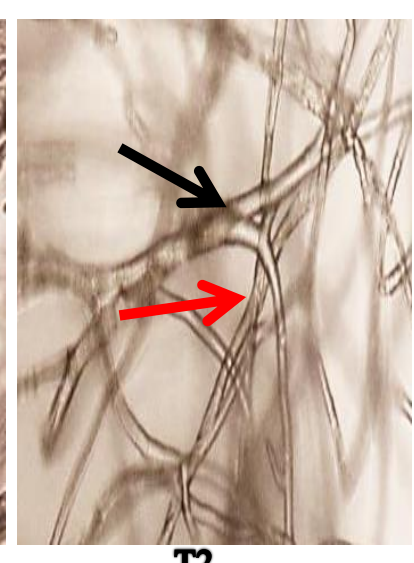

T2

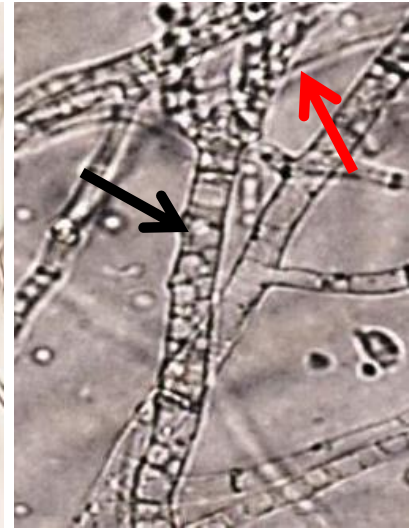

T4

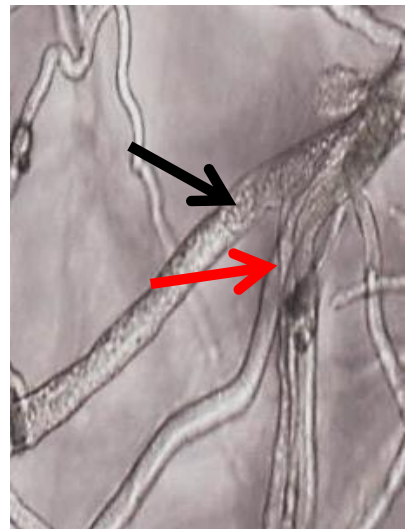

T6

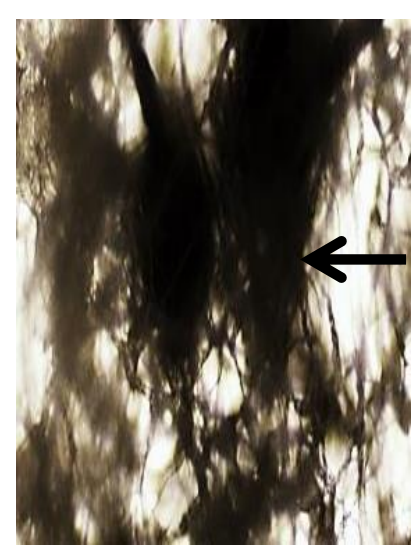

T5

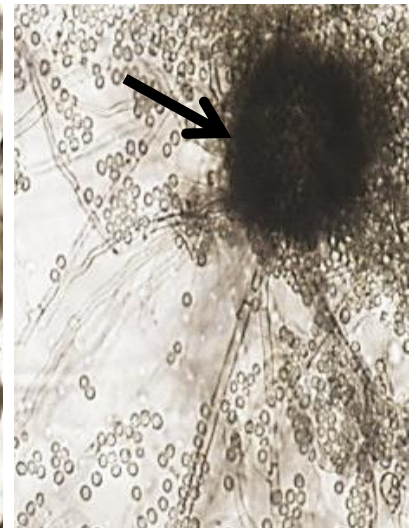

T7

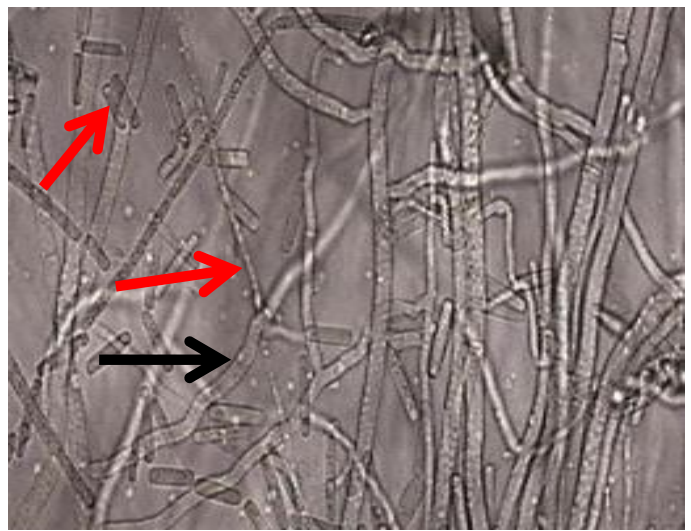

T14

Figure 3 The type of hyperparasitic interaction of the Trichoderma sp. (black arrow) and Ceratocystis sp. (red arrow).

\section{CONCLUSION}

The isolates of $T$. virens endophytic roots of oil palm plants (T1), T. virens endophytes of oil palm stems (T2), T. harzianum endophytes of rubber plant roots (T4), Trichoderma sp. endophytic E074 from 4 years Acacia crasicarpa (T5), Trichoderma sp. endophytic E075 from 4 years Acacia crasicarpa (T6), Trichoderma sp. endophytic
E080 from 3 years Acacia crasicarpa (T7), and Trichoderma sp. endophytic E022 Eucalyptus plants (T14) are seven isolates that have moderate inhibitory ability to control stem rot disease caused by Ceratocystis sp. in vitro.

Isolate Trichoderma sp. endophytic E074 Acacia crasicarpa 4 years (T5 isolate) is the best treatment in inhibiting the pathogen Ceratocystis sp. with the highest 
percentage of inhibitory ability (30.76\%), and the largest colony diameter $(90.00 \mathrm{~mm})$, and the highest growth rate (33.33 mm.day ${ }^{-1}$ ).

\section{ACKNOWLEDGMENT}

This work was supported by Plant Protection Department Laboratory, PT. Arara Abadi to allowed doing this research there.

\section{REFERENCES}

[1] S. Rahayu, H.H.Nurjanto and R.G.Pratama. Character of Ceratocystis sp. Causes of Stem Rot in Acacia decurrens and Its Disease Status in Mount Merapi National Park, Yogyakarta, Journal of Forestry Science. Vol. 9, no. 2, pp. 94-104, 2015.

[2] S.M. Accordi, Spread of Ceratocystis fimbriata platani through root anastomoses. Informatore Fitopatologico, vol. 36, no. 3, pp. 53-58, 1996.

[3] A.T. Kurnia, M. I. Pinem and S. Oemry. Use of endophytic fungi to control Fusarium oxysporum f.sp. capsici and Alternaria solani in vitro, Journal of Agrotechnology. Vol. 2, no. 4, pp. 1596-1606, 2014.

[4] Asdar, 'Utilization of Biological Agents in Inducing Resistance to Cutaneous Disease in Patchouli (Pogostemon cablin Benth.)'. Accessed: 2020. [Online]. Available: http://www.scribd.com/doc/129043916/TesisAsdar-2013.

[5] W. Andini, 'Isolation and Antagonist Test of Endophytic Fungi from Rubber Plants against Rigidoporus microporus by In Vitro and Identification of Endophytic Fungi with Potential to Become Biological Agents', University of Riau, 2018.

[6] N.A. Saputra, 'Test of Antagonists and Potential Anti-fungal Compounds of Three Trichoderma virens isolates TR01, TS02, and TM01 Endophytes of Oil Palm Plants Against Rigidoporus microporus in vitro', University of Riau, 2018.

[7] R.S. Fitriani, and Wulandari, Biological control of root rot pathogens (Ganoderma sp) on Acacia mangium with Trichoderma spp. local isolates in vitro, Journal of sustainable forests, vol. 5, no. 3, pp. 570-571, 2017.

[8] G.E. Harman, T. Bjorkman, K. Ondik, M. Shoresh, 'Trichoderma spp. for biocontrol. Changing paradigms on the mode of action and uses of Trichoderma spp. for biocontrol', Research information. Cornell University, USA. 2008.

[9] M. Hutabalian, M. 1. Pinem and S. Oemry, Antagonism test of several saprophytic fungi from banana plants against Fusarium oxysporum f.sp. cubens, Journal of Agroecotechnology, vol. 3, no. 2, pp. 687695, 2015.

[10] D. Sunarwati and R Yoza,'The ability of Trichoderma and Penicillium to inhibit the growth of the fungus that causes durian root rot disease (Phythopthora palmivora) in vitro'. Proceedings of the National Seminar on National Fruit Development Programs and Strategies, Tropical Fruit Research Institute, Solok, pp. 176-189, 2010.

[11] W. Amaria, E. Taufiq and R. Harni, Selection and identification of antagonistic fungi as biological agents of white root fungus (Rigidoporus microporus) in rubber plants, Bulletin RISTRI, vol. 4, no. 1, pp. 55-64, 2013.

[12] L. Octriana, Potential Biological Agents in Inhibiting Growth of Phytium sp. In vitro. Germplasm Bulletin, vol 17, no. 2, pp. 138142, 2011.

[13] N, Melysa, Fajrin, Suharjono, M. E. D. Astuti, 'Potential of Trichoderma sp. as a controlling agent for Fusarium sp. strawberry plant pathogen (Fragaria sp.)'. Center for citrus and subtropical fruit research. Tlekung, Batu City, 2013.

[14] S. Purwantisari, and R.B. Hastuti, Test for the antagonism of the pathogenic fungus Phytophthora infestans which causes late blight and potato tubers using Trichoderma spp. local isolates. Biome. Vol. 11, no. 1, pp. 24-32, 2009.

[15] Djafarudin, 'Basis for Plant Disease Protection (Dasar-Dasar Perlindungan Tanaman)', Bumi Aksara, 2000.

[16] H.S. Gusnawathy, M. Taufik, Faulika and Asniah, Test the potential of Trichoderma indigenous Southeast Sulawesi as a biofungicide against Phytophthora capsici by 
in-vitro. Journal of Agrotechnology. vol. 3, no. 3, pp. 139-143, 2013.

[17] A.Z. Alamsyah, 'Test of Inhibition of Several Red Chili Endophytic Fungus Isolates against Colletotrichum capsiciand Its Ability to Control Anthracnose Disease in Red Chili', Riau University, 2018.
[18] W. Sari and E. Setiawanto, Potential of banana rhizoafer fungi as biological agents against the fungus Fusarium oxysporum f.sp cubense which causes wilt disease in bananas. Journal of Agroscience. vol. 1, no. 2, pp. 3742, 2015. 